\title{
Optimization of Hydrocarbons Biodegradation by Bacterial Strains Isolated from Wastewaters in Ouagadougou, Burkina Faso: Case Study of SAE 40/50 Used Oils and Diesel
}

\author{
Adama Sawadogo ${ }^{1^{*}}$, Harmonie C. Otoidobiga1, Léon W. Nitiema², Alfred S. Traoré1, \\ Dayéri Dianou ${ }^{3}$ \\ ${ }^{1}$ Research Center for Biological, Alimentary and Nutritional Sciences, Research and Training Unit, Life and Earth \\ Sciences, University of Ouagadougou, Ouagadougou, Burkina Faso \\ ${ }^{2}$ National Center for Scientific and Technological Research, Institute for Environment and Agricultural Research, \\ Ouagadougou, Burkina Faso \\ ${ }^{3}$ National Center for Scientific and Technological Research, Institute for Health Sciences Research, \\ Ouagadougou, Burkina Faso \\ Email: "damouss75@yahoo.fr
}

Received 11 December 2015; accepted 21 February 2016; published 24 February 2016

Copyright (C 2016 by authors and Scientific Research Publishing Inc.

This work is licensed under the Creative Commons Attribution International License (CC BY). http://creativecommons.org/licenses/by/4.0/

(c) (i) Open Access

\section{Abstract}

Environmental pollution with petroleum and petrochemical products such as diesel and used oils has been recognized as one of the most serious current problem in the world, especially in developing countries. These petrochemical products devastate the soil, surface and underground waters and alter the microbial population at the polluted sites. Thus, the present work aims to optimize the biodegradation of diesel and two used oils (SAE 40 and SAE 50) by bacterial strains namely Acinetobacter S2 and Pseudomonas S7 using either nutrient factors (yeast extract, peptone or trace elements) or surfactants (tween 80 or Sodium Dodecyl Sulfate: SDS). The strains are incubated alone or together with the used oils or diesel supplemented or not with nutrient factors or surfactants for 14, 28, 42 and 56 days, respectively. For all the incubation period, the hydrocarbons degradation rates are determined by gravimetric assay. The results obtained show that nutrient factors increase significantly SAE 50 used oil biodegradation $(p=0.009)$. Similarly, tween

*Corresponding author. 
80 increases SAE 50 and SAE 40 used oils biodegradation but not diesel one. The results also show a significant difference between biodegradation rates at 14, 28, 42 and 56 days for all the hydrocarbons tested $(p<0.0001)$. For all the hydrocarbons, the association of strains Acinetobacter S2 and Pseudomonas $\mathbf{S 7}$ increases the degradation over the one of the strains alone.

\section{Keywords}

\section{Biodegradation, Hydrocarbon, Nutrient Factor, Surfactant, Bacterial Strain}

\section{Introduction}

Lubricant oil is a complex mixture of hydrocarbons and other organic compounds, including some organometallic constituents that are used to lubricate the parts of an automobile engine, in order to keep everything running smoothly [1]. The utilization of lubricant leads to the production of used oils commonly in the whole world. The illegal dumping of used oils is an environmental hazard with global ramifications [2]. These used oils devastate the soil, surface and underground water and alter the microbial population at the polluted sites [3]. Spillage of used motor oils also contaminates our natural environment with polycyclic aromatic hydrocarbons (PAHs) which attract public attention because many PAHs are toxic, mutagenic and carcinogenic [4] [5]. Similarly, diesel oil is one of the major products of crude oil that constitutes the main source of pollution in the environment [6]. In addition, soil contamination by hydrocarbons, as well as underground and surface water, seriously affects the ecosystem, especially through the accumulation within animals and plants resulting in death and mutation [7]. Environmental pollution with petroleum and petrochemical products (complex mixtures of hydrocarbons) has been recognized as one of the most serious current problem [8] [9]. Fortunately, bioremediation of petrochemical products in the environment is possible and exploits the metabolic properties of microorganisms (bacteria, yeast or fungi) to degrade these contaminating agents. This ability may be natural or acquired through the acquisition of codifying genes for specific functions [7]. Bioremediation of waste materials which contain hydrocarbons and their derivatives is based on the ability of microorganisms growing on these substrates to increase their biomass and to degrade them to non-toxic products, such as $\mathrm{H}_{2} \mathrm{O}$ and $\mathrm{CO}_{2}$ [10].

The application of bacterial isolates in degrading oil involves the manipulation of environmental parameters to allow microbial growth and degradation to proceed at a faster rate [11]. The intensity of oils biodegradation is influenced by several factors, such as nutrients, oxygen, $\mathrm{pH}$, composition, concentration and bioavailability of the contaminants, chemical and physical characteristics and the pollution history of the contaminated environment [12]. Particularly, lack of essential nutrients such as nitrogen and phosphorus is one of the major factors affecting biodegradation of hydrocarbon by microorganisms in soil and water environment [13]. In addition, studies report the use of surfactants to enhance hydrocarbons biodegradation [14]-[16]. Surfactants are amphipathic molecules with both hydrophilic and hydrophobic (generally hydrocarbon) moieties that partition preferentially at the interface between fluid phases with different degrees of polarity and hydrogen bonding such as oil/water or air/water interfaces [17]. According to Chrzanowski et al. [18], surface-active compounds may generally influence hydrocarbons biodegradation by increasing their solubility or they may interfere with the cell walls of microorganisms.

In our previous works, two bacterial strains able to degrade hydrocarbons were isolated [19]. The optimization of Total Quartz SEA 40 used oil and diesel oil biodegradation by these strains in presence of nutrient factors was also performed [20]. However, the effects of nutrient factors on SAE 50 used oil (oil commonly used in our country because of it low cost) degradation, as well as the effects of surfactants on both hydrocarbons degradation by these strains were not documented. Thus, the present work focused on the optimization of these hydrocarbons biodegradation using nutrient factors (yeast extract, peptone or trace elements) and surfactants (Tween 80 or SDS), respectively.

\section{Material and Methods}

\subsection{Bacterial Strains}

Two bacterial strains, namely S2 and S7 used in this study were isolated during our previous work from waste- 
waters in Ouagadougou, Burkina Faso and partially characterized. Based on their morphological, biochemical and physiological characteristics, the strains S7 and S2 appeared to be related to Pseudomonas and Acinetobacter genera, respectively [19].

\subsection{Hydrocarbons Used in This Study}

The diesel oil used in this experiment was purchased from a local oil filling station and stored in the dark at ambient temperature throughout the study. The used oils (SEA 40 and SAE 50) were collected from a local garage and stored in the same conditions as for diesel oil. Before use, the oils were sterilized using $0.2 \mu \mathrm{m}$ pore size membrane filter.

\subsection{Culture Media and Incubation Condition}

Bushnell-Haas Broth consisting of: $\mathrm{K}_{2} \mathrm{HPO}_{4} 1.0$ g/L, $\mathrm{KH}_{2} \mathrm{PO}_{4} 1.0$ g/L, $\mathrm{NH}_{4} \mathrm{NO}_{3} 1.0$ g/L, $\mathrm{MgSO}_{4} 0.2$ g/L, $\mathrm{CaCl}_{2}$ $0.02 \mathrm{~g} / \mathrm{L}$ and $\mathrm{FeCl}_{3} 0.005 \mathrm{~g} / \mathrm{L}$ was used for incubation. Flasks $(120 \mathrm{ml}$ ) containing $35.6 \mathrm{ml}$ of the nutrient broth supplemented with $3 \%(\mathrm{v} / \mathrm{v})$ of $0.22 \mu \mathrm{m}$ pore size filter-sterilized hydrocarbon substrate were inoculated in triplicate with $4 \mathrm{ml}$ exponential phase culture inoculum of Acinetobacter S2 and Pseudomonas S7 strains or their mixture (Acinetobacter S2 + Pseudomonas S7), respectively and then incubated at $37^{\circ} \mathrm{C}$ for 14, 28, 42 and 56 days ( $2 \mathrm{ml}$ of the suspension of each strain culture was added in the case of the mix culture S2 + S7). Controls without bacterial inoculation were prepared similarly for all incubations to evaluate the abiotic loss of hydrocarbons. The $\mathrm{pH}$ was adjusted to 8.00, 7.50 and 7.75 for cultures containing bacterial strains S2, S7 and their mixture (S2 + S7), respectively. To test the effects of nutrient factors, the above cultures were supplemented with $0.5 \%(\mathrm{w} / \mathrm{v})$ yeast extract or peptone and $1 \%(\mathrm{v} / \mathrm{v})$ trace elements of Widdel and Pfennig [21], respectively. The Widdel and Pfennig trace elements consists of: $\mathrm{HCl}\left(25 \%\right.$ : v/v) $6.5 \mathrm{ml}, \mathrm{FeCl}_{2} \cdot 4 \mathrm{H}_{2} \mathrm{O} 1.5 \mathrm{~g}, \mathrm{H}_{3} \mathrm{BO}_{3} 60 \mathrm{mg}$, $\mathrm{MnCl}_{2} \cdot 4 \mathrm{H}_{2} \mathrm{O} 100 \mathrm{mg}, \mathrm{CoCl}_{2} \cdot 6 \mathrm{H}_{2} \mathrm{O} 120 \mathrm{mg}, \mathrm{ZnCl}_{2} 70 \mathrm{mg}, \mathrm{NiCl}_{2} \cdot \mathrm{H}_{2} \mathrm{O} 25 \mathrm{mg}, \mathrm{CuCl}_{2} \cdot 2 \mathrm{H}_{2} \mathrm{O} 15 \mathrm{mg}, \mathrm{Na}_{2} \mathrm{MoO}_{4} \cdot 2 \mathrm{H}_{2} \mathrm{O}$ $25 \mathrm{mg}$, distilled water $1000 \mathrm{ml}$ final volume. To evaluate the effects of surfactants on the biodegradation process, $0.5 \%(\mathrm{v} / \mathrm{v})$ Tween 80 or $0.5 \%(\mathrm{w} / \mathrm{v})$ SDS was added to the Bushnell-Haas Broth cultures described above.

\subsection{Biodegradation Study}

Hydrocarbon degradation was studied by gravimetric analysis according to Marquez-Rocha et al. [22] and Panda et al. [23]. After different incubation periods at $37^{\circ} \mathrm{C}$, the flasks $(120 \mathrm{ml})$ were taken out and bacterial activities were stopped by adding $1 \%(\mathrm{v} / \mathrm{v}) 1 \mathrm{~N}-\mathrm{HCL}$. For extraction of residual oil, $40 \mathrm{ml}$ of culture broth was mixed with $40 \mathrm{ml}$ petroleum ether/acetone (1:1) in a separating funnel and then shaken vigorously to get a single emulsified layer. Acetone was then added and shaken gently to break the emulsification, which resulted in three layers. The top layer was a mixture of petroleum ether, diesel oil and acetone; clumping cells make a middle layer and the bottom aqueous layer contains acetone, water and biosurfactant in soluble form. The lower two layers were spread out while the top layer containing petroleum ether mixed with diesel oil or used oils and acetone was taken in a preweighed clean beaker. The extracted oil was passed through anhydrous sodium sulphate to remove moisture. The petroleum ether and acetone layer was evaporated on a water bath. The gravimetric estimation of residual oil left after biodegradation was made by weighing the quantity of oil in a tarred beaker. The percentage of biodegraded oil was then evaluated in comparison to the initial hydrocarbon amount in the control funnel according to Fusey and Oudot [24], as described by Sawadogo et al. [19].

\subsection{Statistical Analysis}

The data collected were subjected to analysis of variance (ANOVA) with regards to the hydrocarbon used, nutrient factor, surfactant, incubation period and bacterial strain using XLSTAT-Pro 7.5 software. Mean variables were compared using the Newman Keuls test at probability level $p=0.05$.

\section{Results and Discussion}

\subsection{Effects of Nutrient Factors on SAE 50 Used Oil Biodegradation}

The statistical analysis showed that bacterial strain has a significant effect on SAE 50 used oil biodegradation ( $p=0.00$, Table 1). It also showed that nutrient factor have a significant effect on SAE 50 used oil biodegrada- 
tion ( $p=0.009$, Table 1). Similarly, the combined effect of bacterial strain and nutrient factor was also significant $(p<0.0001$, Table 1$)$.

After 14 days incubation period at $37^{\circ} \mathrm{C}$, biodegradation rates of $16.88 \% \pm 0.85 \%, 26.08 \% \pm 1.9 \%, 18.83 \% \pm$ $0.36 \%, 16.71 \% \pm 0.26 \%$ were found for Acinetobacter S2 on SAE 50 used oil and SAE 50 used oil supplemented with yeast extract, peptone or trace elements, respectively, while biodegradation rates of $13.41 \pm 1.9$, $19.05 \pm 2.3,15.46 \pm 0.53,14.01 \pm 0.72$ were obtained for Pseudomonas S7 on the same substrates, respectively.

As variance analysis showed, for all the substrates, the biodegradation rates obtained in presence of strain S2 are always higher than those obtained in presence of strain S7 (Figure 1). This result could be explained by the high growth rates of strain S2 compared to those of strain S7 [19]. This relation between strain growth rate and hydrocarbon biodegradation was demonstrated by Mandri and Lin [25].

All the organic nutrient factors (yeast extract and peptone) increased the SAE 50 used oil biodegradation. For all the bacterial strains and substrates, the biodegradation rates recorded in presence of yeast extract are significantly higher compared to those recorded in presence of peptone $(p<0.0001$, Table 1$)$. The increase of biodegradation rates in presence of nutrient factors could be explained by the presence of phosphorus and nitrogen in these nutrient factors. According to some authors [26]-[28], nitrogen and phosphorus are known as the most important nutrients needed by hydrocarbon-utilizing bacteria to carry out effective and efficient degradation of xenobiotics in the environment.

Table 1. Variance of SAE 50 used oil biodegradation with regards to bacterial strain (Acinetobacter S2 or Pseudomonas S7) and nutrient factor (yeast extract, peptone and trace elements) (means of 3 replicates).

\begin{tabular}{ccc}
\hline Source of variation & df & $p \quad 0.00$ \\
Bacterial strain & 1 & $\mathrm{f}$ \\
Nutrient factor & 2 & 0.001 \\
Nutrient factor X bacterial strain & 5 & $<0.0001$ \\
\hline
\end{tabular}

s: Significant; df: Degree of freedom; $p=$ Probability at a risk of 5\%; f: F-test.

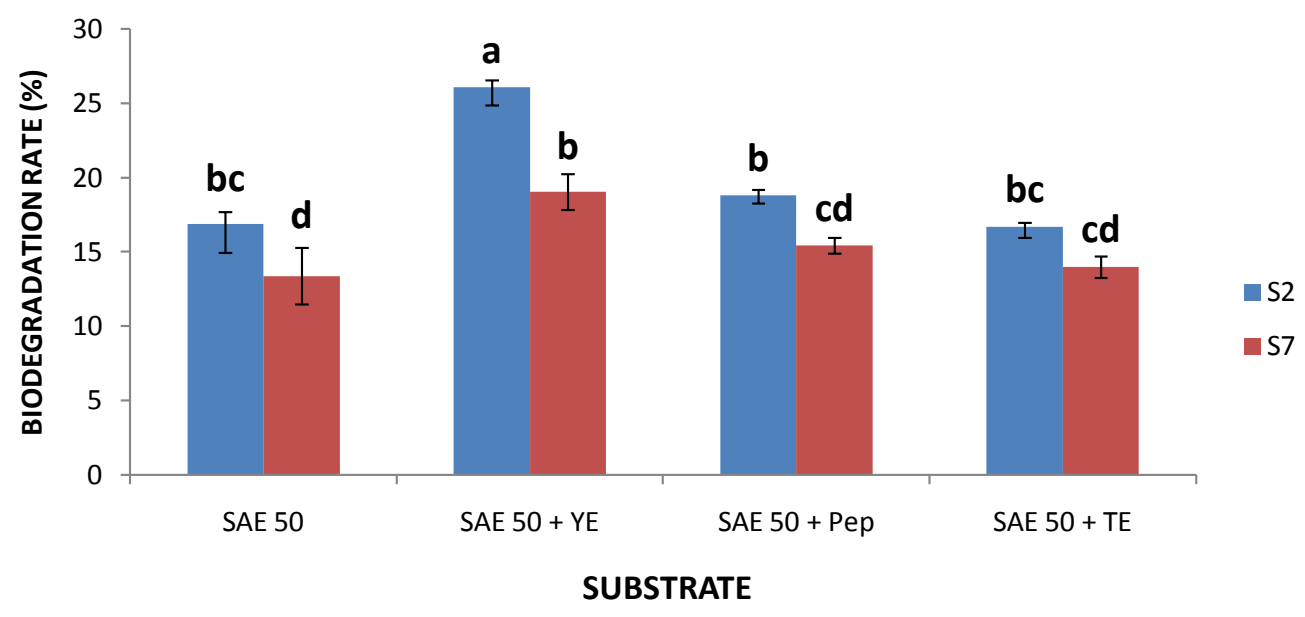

Figure 1. Biodegradation rates of Acinetobacter S2 and Pseudomonas S7 strains on SAE 50 used oil supplemented or not with nutrient factors after 14 days incubation period. For all strains and for all the substrates experienced, values sharing the same letter are not significantly different according to the Newman-Keuls’ test at $p=0.05$. YE: Yeast Extract; Pep: Peptone; TE: Trace Elements.

The results also showed a low increase of biodegradation rates on this hydrocarbon supplemented with trace elements compared to the control without trace elements (Figure 1). According to Springgate et al. [29], trace elements can increase bacterial enzyme activity as cofactors and then, leading to bacterial growth. This increase of bacterial growth could explain the increase in the biodegradation rate of hydrocarbons supplemented with trace elements. Thus, some authors use trace elements to supplemented culture media during hydrocarbons bio- 
degradation [30]-[32].

\subsection{Effects of SDS and tween 80 on Diesel Oil, SAE 40 and SAE 50 Used Oils Biodegradation}

\subsubsection{Case of Diesel Oil}

The statistical analysis showed no significant effect of surfactant on diesel oil biodegradation $(p=0.995$, Table 2). However, a significant effect was found for bacterial strain on diesel oil biodegradation ( $p<0.0001$, Table 2). Similarly, the combined effects of bacterial strain and surfactant also showed a significant effect on diesel oil biodegradation $(p<0.0001$, Table 2$)$.

Table 2. Variance of hydrocarbons (diesel oil, SAE 40 and SAE 50 used oils) biodegradation with regards to bacterial strain (Acinetobacter S2, Pseudomonas S7) and surfactant (tween 80, SDS) (means of 3 replicates).

\begin{tabular}{|c|c|c|c|c|c|c|c|}
\hline \multirow{2}{*}{ Source of variation } & \multirow{2}{*}{ df } & \multicolumn{2}{|c|}{ Diesel oil } & \multicolumn{2}{|c|}{ SAE 40 used oil } & \multicolumn{2}{|c|}{ SAE 50 used oil } \\
\hline & & $p$ & $\mathrm{f}$ & $p$ & $\mathrm{f}$ & $p$ & $\mathrm{f}$ \\
\hline Bacterial strain & 1 & $<0.0001$ & s & 0.031 & s & 0.000 & $\mathrm{~s}$ \\
\hline Surfactant & 1 & 0.995 & ns & 0.030 & s & 0.112 & ns \\
\hline Bacterial strain x surfactant & 3 & $<0.0001$ & s & 0.009 & s & $<0.0001$ & $\mathrm{~s}$ \\
\hline
\end{tabular}

ns: Not significant; s: Significant; df: Degree of freedom; $p=$ Probability at a risk of 5\%; f: F-test.

After 14 days incubation period at $37^{\circ} \mathrm{C}$, the highest biodegradation rate was observed with strain $\mathrm{S} 2$ on diesel oil supplemented with tween $80(30.81 \% \pm 0.63 \%$, Table 3$)$, and the lowest biodegradation rate was recorded with strain S7 on diesel oil supplemented with SDS (18.14\% $\pm 0.30 \%$, Table 3$)$. The biodegradation rates recorded on diesel oil + tween 80 are rather higher than those observed on diesel oil alone or diesel + SDS. However, as revealed by the variance analysis, for both bacterial strains, no significant effect was found for tween 80 and SDS on diesel oil biodegradation ( $p=0.995$, Table 2). For all the substrates, the biodegradation rates recorded with strain S2 are significantly higher than those observed with strain S7 ( $p<0.0001$, Table 2).

Table 3. Biodegradation rates of diesel oil supplemented or not with surfactant (tween 80 or SDS) after 14 days incubation period with regards to Acinetobacter S2 and Pseudomonas S7 strains.

\begin{tabular}{ccc}
\hline Substrate & Bacterial strain & Biodegradation rate (\%) \\
\hline \multirow{2}{*}{ Diesel oil } & Acinetobacter S2 & $30.57^{\mathrm{a}} \pm 1.09$ \\
& Pseudomonas S7 & $18.25^{\mathrm{b}} \pm 1.30$ \\
Diesel oil + Tween 80 & Acinetobacter S2 & $30.81^{\mathrm{a}} \pm 0.63$ \\
& Pseudomonas S7 & $18.32^{\mathrm{b}} \pm 0.38$ \\
Diesel oil + SDS & Acinetobacter S2 & $30.25^{\mathrm{a}} \pm 0.53$ \\
& Pseudomonas S7 & $18.14^{\mathrm{b}} \pm 0.30$ \\
\hline
\end{tabular}

Means with a same letter within a column are not significantly different according to the Newman-Keuls' test at $p=0.05$.

\subsubsection{Case of SAE 40 Used Oil}

The statistical analysis showed a significant effect for surfactant and bacterial strain on SAE 40 used oil biodegradation, respectively ( $p=0.030$ and $p=0.031$, Table 2). Similarly, the combined effects of bacterial strain and surfactant showed a significant effect on SAE 40 used oil biodegradation ( $p=0.009$, Table 2). The variance analysis is in agreement with the results obtained after biodegradation. Thus, the biodegradation rates recorded in presence of tween $80(18.15 \% \pm 0.4 \%$ and $16.76 \% \pm 0.55 \%$ with strains S2 and S7, respectively, Table 4$)$ are significantly higher than those recorded on SAE 40 used oil supplemented with SDS or not ( $p=0.009$, Table 2). For all the substrates, the biodegradation rates recorded with Acinetobacter S2 are higher than those observed with Pseudomonas S7 (Table 4). 
Table 4. Biodegradation rates of SAE 40 used oil supplemented or not with surfactant (tween 80 or SDS) after 14 days incubation period, with regards to Acinetobacter S2 and Pseudomonas S7 strains. Acinetobacter S2 and Pseudomonas S7.

\begin{tabular}{|c|c|c|}
\hline Substrate & Bacterial strain & Biodegradation rate (\%) \\
\hline \multirow{2}{*}{ SAE 40 used oil } & Acinetobacter S2 & $15.46^{\mathrm{bc}} \pm 1.24$ \\
\hline & Pseudomonas S7 & $13.73^{\mathrm{c}} \pm 1.51$ \\
\hline \multirow{2}{*}{ SAE 40 used oil + Tween 80} & Acinetobacter S2 & $18.15^{\mathrm{a}} \pm 0.46$ \\
\hline & Pseudomonas S7 & $16.76^{\mathrm{ab}} \pm 0.55$ \\
\hline \multirow{2}{*}{ SAE 40 used oil + SDS } & Acinetobacter S2 & $16.86^{\mathrm{ab}} \pm 0.69$ \\
\hline & Pseudomonas S7 & $13.81^{\mathrm{c}} \pm 0.21$ \\
\hline
\end{tabular}

Means with a same letter within a column are not significantly different according to the Newman-Keuls’ test at $p=0.05$.

\subsubsection{Case of SAE 50 Used Oil}

The statistical analysis showed no significant effect for surfactant on SAE 50 used oil biodegradation $(p=0.112$, Table 2). In contrast, bacterial strain influenced significantly SAE 50 used oil biodegradation. ( $p=0.000$, Table 2). Similarly, the combined effects of bacterial strain and surfactant showed a significant effect on SAE 50 used oil biodegradation $(p<0.0001$, Table 2). The results obtained showed that for both strains, the biodegradation rates observed in presence of tween 80 are higher than those recorded with SDS (Table 5). For all the substrates, the biodegradation rates recorded with Acinetobacter S2 are higher than those observed with Pseudomonas S7 (Table 5). The biodegradation rate recorded with Acinetobacter S2 on SAE 50 used oil supplemented with tween 80 is significantly higher than those recorded in other cases $(p<0.0001$, Table 2).

Table 5. Biodegradation of SAE 50 used oil supplemented or not with surfactants (tween 80 and SDS) after 14 days incubation period, with regards to Acinetobacter S2 and Pseudomonas S7 strains.

\begin{tabular}{ccc}
\hline Substrate & Bacterial strain & Biodegradation rate (\%) \\
\hline \multirow{2}{*}{ SAE 50 used oil } & Acinetobacter S2 & $16.88^{\mathrm{b}} \pm 0.85$ \\
& Pseudomonas S7 & $13.41^{\mathrm{c}} \pm 1.90$ \\
SAE 50 used oil + Tween 80 & Acinetobacter S2 & $18.83^{\mathrm{a}} \pm 0.32$ \\
& Pseudomonas S7 & $16.01^{\mathrm{b}} \pm 0.67$ \\
SAE 50 used oil + SDS & Acinetobacter S2 & $16.99^{\mathrm{b}} \pm 0.18$ \\
& Pseudomonas S7 & $13.63^{\mathrm{c}} \pm 0.32$ \\
\hline
\end{tabular}

Means with a same letter within a column are not significantly different according to the Newman-Keuls' test at $p=0.05$.

For all the hydrocarbons used in this study, the results obtained after 14 days incubation period showed that tween 80 increases the biodegradation rates of the two used oils (SAE 40 and SAE 50) but not the those of diesel oil (Tables 3-5). According to some authors, surfactant can increase the solubility of certain compounds such as hydrocarbons and by then, can facilitate the access of these compounds to microbial cell. This increase of microbial access to hydrocarbon could explain the increase of biodegradation rates. Thus, Celik et al. [33], studying the biodegradation of crude oil by a Pseudomonas strain found that the biodegradation rate increased from $60 \%$ (in absence of surfactant) to $76 \%$ and $96 \%$, respectively in presence of $1 \%(\mathrm{v} / \mathrm{v})$ of triton X-100 or tween 80. Similarly, several researches reported that the use of surfactant enhances the degradation of crude oil [16] [34]. According to Chrzanowski et al. [18], surfactant can facilitate hydrocarbons entry in cell walls of microorganisms and then can increase their biodegradation. In the case of diesel oil, the presence of tween 80 did not increase the biodegradation rate. This result could be explained by the fact that diesel is more soluble than used oils [35]. The presence of SDS did not increase the hydrocarbons biodegradation (Tables 3-5). According to Tiehm [36], SDS can be used as growth substrate for microorganisms during hydrocarbons biodegradation and then, can lead to reduced hydrocarbons utilization.

Overall, for the incubation period tested, the study showed that among the factors used to increase the biodegradation of the hydrocarbons, yeast extract revealed the best effect. Therefore, this factor is tested for an extend incubation period (i.e. 28, 42 and 56 days, respectively) in the same conditions described above. 


\subsection{Effect of Incubation Period on Diesel Oil, SEA 40 and SAE 50 Used Oils Biodegradation}

\subsubsection{Case of Diesel Oil}

The variance analysis showed that the incubation period increased significantly diesel oil degradation, as well as the combined effect of bacterial strain and incubation period ( $p<0.0001$, Table 6). A significant difference between Acinetobacter S2 and Pseudomonas S7 strains mixture and the strains alone for diesel oil biodegradation was also evidenced ( $p=0.002$, Table 6$)$.

Table 6. Variance of hydrocarbons (diesel oil, SAE 40 and SAE 50 used oils) biodegradation with regards to bacterial strain (Acinetobacter S2, Pseudomonas S7 or their mixture) and incubation period (means of 3 replicates).

\begin{tabular}{|c|c|c|c|c|c|c|c|}
\hline \multirow{2}{*}{ Source of variation } & \multirow{2}{*}{ df } & \multicolumn{2}{|c|}{ Diesel oil } & \multicolumn{2}{|c|}{ SAE 40 used oil } & \multicolumn{2}{|c|}{ SAE 50 used oil } \\
\hline & & $p$ & $\mathrm{f}$ & $p$ & $\mathrm{f}$ & $p$ & $\mathrm{f}$ \\
\hline Bacterial strain & 2 & 0.002 & $\mathrm{~s}$ & 0.010 & $\mathrm{~s}$ & 0.009 & $\mathrm{~s}$ \\
\hline Incubation period & 3 & $<0.0001$ & s & $<0.0001$ & $\mathrm{~s}$ & $<0.0001$ & $\mathrm{~s}$ \\
\hline Bacterial strain $x$ Incubation period & 11 & $<0.0001$ & s & $<0.0001$ & $\mathrm{~s}$ & $<0.0001$ & $\mathrm{~s}$ \\
\hline
\end{tabular}

s: Significant; df: Degree of freedom; $p=$ Probability at a risk of 5\%; f: F-test.

The results obtained showed that the biodegradation rates increased regularly and significantly up to the 56th day in presence of bacterial strains (S2, S7 and their mixture S2 + S7) $(p<0.0001$, Table 6). For all the strains, the biodegradation rates were higher in presence of yeast extract as compared to those recorded in absence of yeast extract. The biodegradation rates increased more rapidly especially after 42 days incubation period in presence of yeast extract. At each incubation period, in presence or not with yeast extract, the biodegradation rates recorded with the strains mixture (S2 + S7) were always higher than those obtained with the strains S2 or S7 alone (Figure 2).

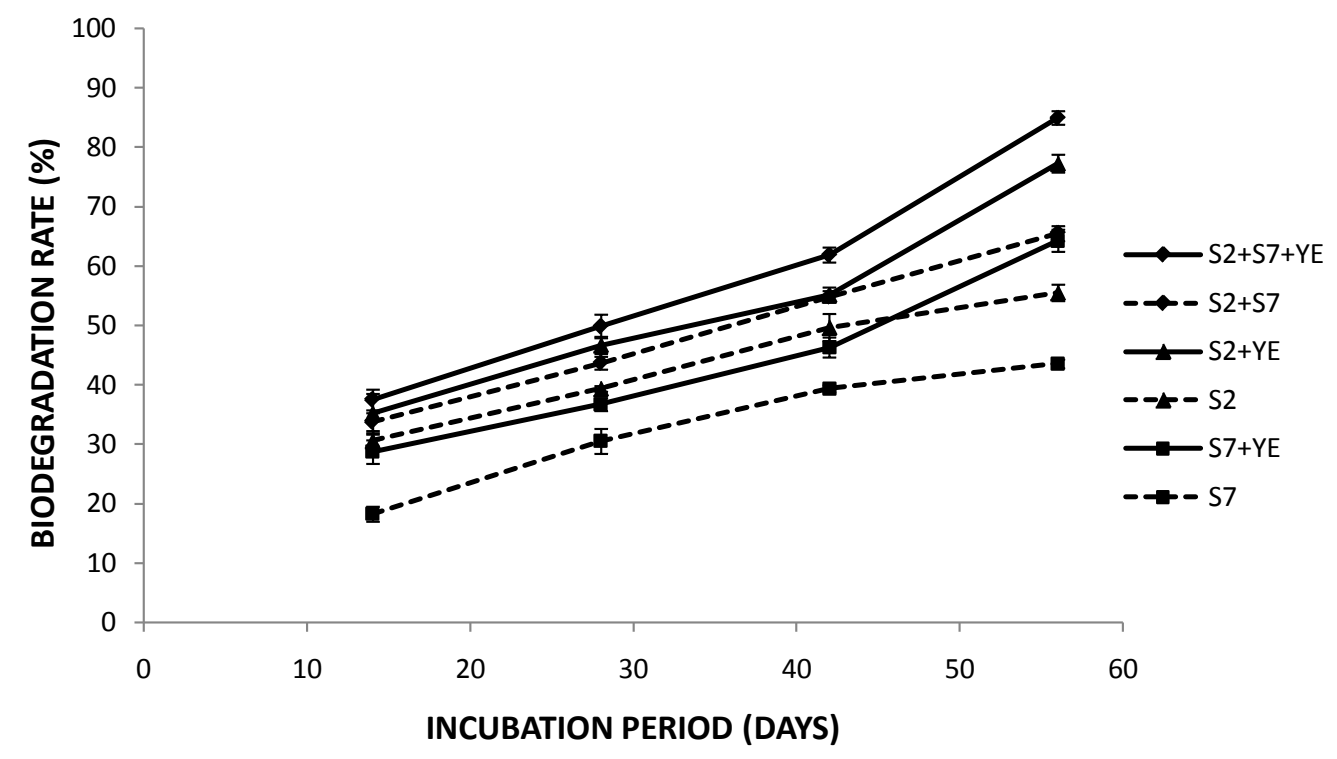

Figure 2. Biodegradation of diesel oil (supplemented or not with yeast extract) by Acinetobacter S2 and Pseudomonas S7 strains, with regards to incubation period. YE: Yeast Extract.

\subsubsection{Case of SAE 40 and SAE 50 Used Oils}

The variance analysis revealed significant impacts of the incubation period on SAE 40 and SAE 50 used oils ( $p<$ 0.0001 , Table 6). The combined effect of incubation period and strain also increased significantly the degradation of SAE 40 and SAE 50 used oils ( $p<0.0001$, Table 6). Significant differences between the bacterial strains mixture (S2 + S7) and the strains S2 or S7 alone for SAE 40 and SAE 50 used oils respective degradation were 
also recorded ( $p=0.010$ and $p=0.009$, Table 6).

The data obtained showed gradual and significant increases of SAE 40 and SAE 50 used oils biodegradation rates from the 14th to the 56th day incubation period for strains S2, S7 and their mixture (S2 + S7) in presence or absence of yeast extract ( $p<0.0001$, Figure 3 \& Figure 4). SAE 40 and SAE 50 used oils biodegradation rates recorded in presence of yeast extract were always higher than those obtained in absence of yeast extract for all the bacterial strains, throughout the incubation periods (Figure 3 \& Figure 4).

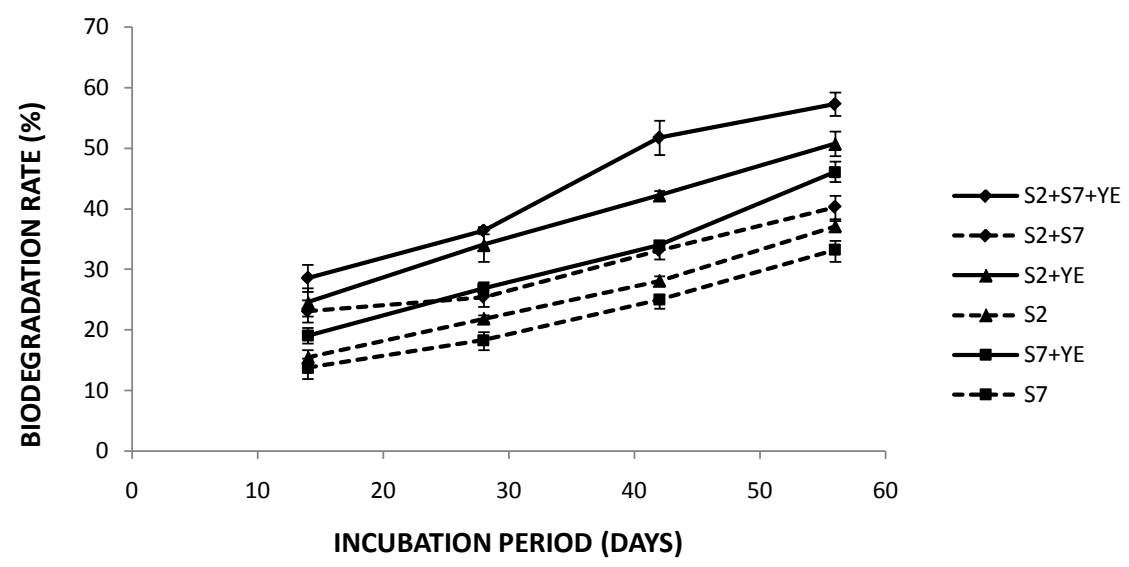

Figure 3. Biodegradation of SAE 40 used oil (supplemented or not with yeast extract) by Acinetobacter S2 and Pseudomonas S7 strains, with regards to incubation period. YE: Yeast Extract.

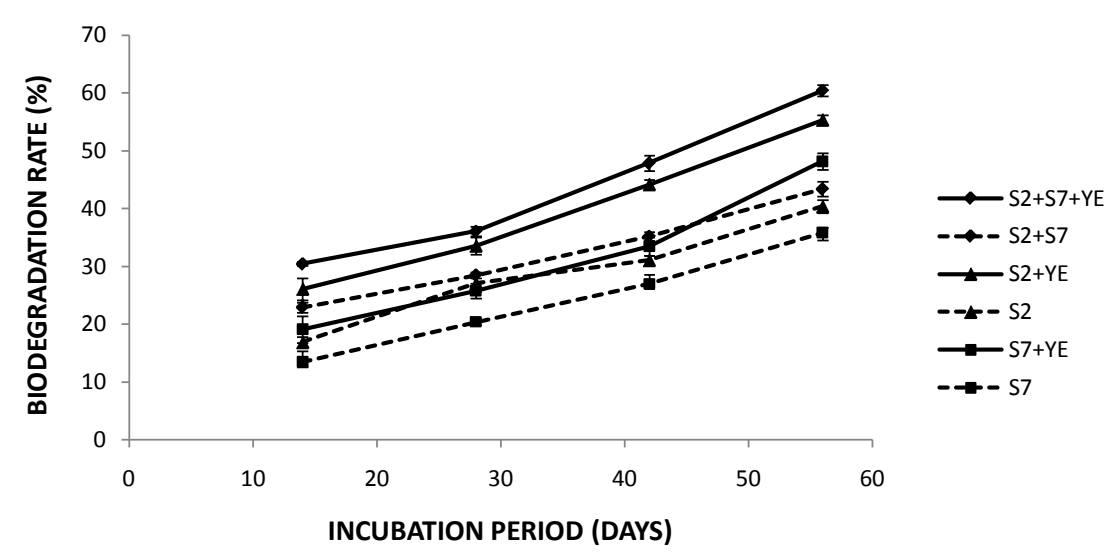

Figure 4. Biodegradation of SAE 50 used oil (supplemented or not with yeast extract) by Acinetobacter S2 and Pseudomonas S7 strains, with regards to incubation period. YE: Yeast Extract.

The results obtained after different incubation periods showed that the biodegradation rates of the three hydrocarbons used in this study increase regularly with regards to incubation period. This increase of hydrocarbons biodegradation with incubation period is also reported by some authors. Thus, Panda et al. [23] found that the biodegradation rates of $0.5 \%(\mathrm{v} / \mathrm{v})$ diesel oil in water increase from $8.22 \%$ to $29.94 \%$ and $30.95 \%$ after 5,10 and 15 days incubation period, respectively. Similarly, Nikhil et al. [37] showed that the biodegradation of diesel increases regularly after $5,10,15,20$ and 25 days incubation time.

According to Panda et al. [23], the biodegradation rates recorded in diesel by a strain namely SI remained higher than those obtained from a strain SII after 5, 10, 15 and 20 days incubation period. However, according to Nikhil et al. [37], the rates of diesel oil biodegradation by a mixture of two strains were lower than those of the strains used separately until the 15th day. From the 20th day, biodegradation rates obtained from the mixture of strains became higher than those obtained from individual strain. In our case, the results also showed that the biodegradation rates obtained with the strains mixture (S2 + S7) are higher than the biodegradation rates rec- 
orded with the strains S2 or S7 alone after 14, 28, 42 and 56 days incubation period. These results are in agreement with those of Nikhil et al. [37] who obtained 90\% biodegradation rate on diesel oil with Micrococcus sp. and Pseudomonas sp. strains mixture. In contrast $68 \%$ and $54 \%$ biodegradation rates were obtained on diesel oil with Pseudomonas sp and Micrococcus sp incubated alone. Similarly, Chekroud et al. [38] showed that bacterial consortium degrades hydrocarbons better than strains used alone. This synergy between bacterial strains leading to an increase of hydrocarbons biodegradation could be explained by an additional effect of enzymes present in each bacterial strain [39].

\subsection{Comparison of Hydrocarbons (Diesel Oil, SAE 40 and SAE 50 Used Oils) Biodegradation with Regards to Incubation Period}

Statistical analysis showed a significant difference between diesel oil and the SAE 40/50 used oils biodegradation ( $p<0.0001$, Table 7). Similarly, the incubation period showed a significant effect on hydrocarbons biodegradation $(p<0.0001$, Table 7). The combined effects of hydrocarbon and incubation period also showed a significant effect on hydrocarbons biodegradation ( $<<0.0001$, Table 7).

Table 7. Variance of hydrocarbons (diesel oil, SAE 40 and SAE 50 used oils) biodegradation by Acinetobacter S2 and Pseudomonas S7 strains, with regards to substrate and incubation period (means of three replicates).

\begin{tabular}{|c|c|c|c|}
\hline Source of variation & df & $p$ & $\mathrm{f}$ \\
\hline Substrate & 2 & $<0.0001$ & $\mathrm{~S}$ \\
\hline Incubation period & 3 & $<0.0001$ & $\mathrm{~s}$ \\
\hline Incubation period x Substrate & 11 & $<0.0001$ & $\mathrm{~s}$ \\
\hline
\end{tabular}

s: Significant; df: Degree of freedom; $p=$ Probability at a risk of 5\%; f: F-test.

As revealed the variance analysis, the biodegradation rates recorded on diesel oil were higher than those recorded on SAE 40 and SAE 50 used oils (Tables 3-5). For the two used oils, the biodegradation rates are not very different (Table 4 and Table 5).

The highest biodegradation rates recorded on diesel oil could be explained by its high solubility as compared to those of the used oils [35]. In addition, used oils generally contain trace elements which can become toxic for many organisms at certain concentration [40]. This toxic effect of trace elements could explain the lowest biodegradation rates recorded on SAE 40 and SAE 50 used oils.

\section{Conclusion}

This study show that Acinetobacter S2 and Pseudomonas S7 strains and their association are able to degrade SAE 40/50 used oils and diesel oil after 14 days incubation period, and more efficiently for an extend incubation period. Organic nutrient factors such as yeast extract and peptone are appeared to increase the biodegradation of these hydrocarbons. Moreover, surfactant like tween 80 reveals the capability to enhance the hydrocarbons biodegradation. Therefore, nutrient factors (yeast extract and peptone) and surfactant (tween 80) can be utilized effectively to reclaim water contaminated with diesel and used oils.

\section{Acknowledgements}

The authors would like to express profound gratitude to WAAPP-PPAAO/INERA-CNS-FL, PACER-UEMOA, CRSBAN-RABIOTECH, UFR-SVT/UO and CNRST/IRSS, for financial and technical supports.

\section{References}

[1] Butler, C.S. and Mason, J.R. (1997) Structure-Function Analysis of the Bacterial Aromatic Ring-Hydroxylating Dioxygenases. Advanced Microbial Physiology, 38, 47-84. http://dx.doi.org/10.1016/S0065-2911(08)60155-1

[2] Blodgett, W.C. (2001) Water-Soluble Mutagen Production during the Bioremediation of Oil-Contaminated Soil. Florida Scientist, 60, 28-36.

[3] Ainon, H., Amir, R., Raja, F., Hanim, R.A. and Noor, A.Y. (2010) Isolation and Characterization of Bacteria Degrading Sumandak and South Angsi Oils. Sains Malaysiana, 39, 161-168. 
[4] Bumpus, J.A. (1989) Biodegradation of Polycyclic Aromatic Hydrocarbons by Phanerochaete Chrysosporium. Applied and Environmental Microbiology, 55, 154-158.

[5] Cerniglia, C.E. and Sutherland, J.B. (2001) Bioremediation of Polycyclic Aromatic Hydrocarbons by Ligninolytic and Non-Ligninolytic Fungi. In: Gadd, G.M., Ed., Fungi in Bioremediation, Cambridge University Press, Cambridge, 136187. http://dx.doi.org/10.1017/cbo9780511541780.008

[6] Adesodun, J.K. and Mbagwu, J.S.C. (2008) Biodegradation of Waste-Lubricating Petroleum Oil in a Tropical Alfisol as Mediated by Animal Droppings. Bioresource Technology, 99, 5659-5665. http://dx.doi.org/10.1016/j.biortech.2007.10.031

[7] Ilyina, A., Castillo, S.M.I., Villarreal, S.J.A., Ramirez, E.G. and Candelas, R.J. (2003) Isolation of Soil Bacteria for Bioremediation of Hydrocarbon Contamination. Becth, Mock, УH-TA, CEP, 2. T., 44, 88-91.

[8] Plohl, K. and Leskovsek, H. (2002) Biological Degradation of Motor Oil in Water. Acta Chimica Slovenica, 49, 279289.

[9] Ghosh Apurba, R., Padmanabha, C. and Sandipan, P. (2006) Impact of Diesel oil Effluent in the Mucosal Surface of the Alimentary Canal of Oreochromis nilotica (Linnaeus): A Scanning Electron Microscopic Study. Journal of Environmental Biology, 27, 129-134.

[10] Toledo, F.L., Calvo, C., Rodelas, B. and Lopez, J.G. (2006) Selection and Identification of Bacteria Isolated from Waste Crude Oil with Polycyclic Aromatic Hydrocarbons Removal Capacities. Systematic and Applied Microbiology, 29, 244-252. http://dx.doi.org/10.1016/j.syapm.2005.09.003

[11] Vidali, M. (2001) Bioremediation: An Overview. Pure Applied Chemistry, 73, 1163-1172. http://dx.doi.org/10.1351/pac200173071163

[12] Al-Darbi, M., Saeed, M.N.O. and Islam, M.R. (2005) Biodegradation of Natural Oils in Seawater. Energy Sources, 27, 19-34. http://dx.doi.org/10.1080/00908310490448073

[13] Abioye, O.P., Agamuthu, P. and Abdul, A.A.R. (2012) Biodegradation of Used Motor Oil in Soil Using Organic Waste Amendments. Biotechnology Research International, 2012, 1-8. http://dx.doi.org/10.1155/2012/587041

[14] Mulligan, C.N., Yong, R.N. and Gibbs, B.F. (2001) Surfactant-Enhanced Remediation of Contaminated Soil: A Review. Engineering Geology, 60, 371-380. http://dx.doi.org/10.1016/S0013-7952(00)00117-4

[15] Rahman, K.S.M., Banat, I.M., Thahira-Rahman, J., Thayumanavan, T. and Lakshmanaperumalsamy, P. (2002) Bioremediation of Gasoline Contaminated Soil by a Bacterial Consortium Amended with Poultry Litter, Coir Pith and Rhamnolipid Biosurfactant. Bioresource Technology, 81, 25-32. http://dx.doi.org/10.1016/S0960-8524(01)00105-5

[16] Urum, K., Pekdemir, T. and Gopur, M. (2003) Optimum Conditions for Washing of Crude Oil-Contaminated Soil with Biosurfactant Solutions. Process Safety and Environmental Protection, 81, 203-209. http://dx.doi.org/10.1205/095758203765639906

[17] Desai, J.D. and Banat, I.M. (1997) Microbial Production of Surfactants and Their Commercial Potential. Microbiology and Molecular Biology Reviews, 61, 47-64.

[18] Chrzanowski, Ł., Kaczorek, E. and Olszanowski, A. (2006) The Ability of Candida Maltosa for Hydrocarbon and Emulsified Hydrocarbon Degradation. Polish Journal of Environmental Studies, 15, 47-51.

[19] Sawadogo, A., Otoidobiga, C.H., Sawadogo, J.B., Kaboré, A., Traoré, A.S. and Dianou, D. (2014) Isolation and Characterization of Hydrocarbon-Degrading Bacteria from Wastewaters in Ouagadougou, Burkina Faso. Journal of Environmental Protection, 5, 1183-1196. http://dx.doi.org/10.4236/jep.2014.512115

[20] Sawadogo, A., Otoidobiga, C.H., Kaboré, A., Sawadogo, J.B., Traoré, A.S. and Dianou, D. (2015) Optimization of Hydrocarbons Biodegradation by Bacterial Strains Isolated from Wastewaters in Ouagadougou, Burkina Faso: Case Study of Diesel and Used Lubricating Oils. Current Research in Microbiology and Biotechnology, 3, 652-657.

[21] Widdel, F. and Pfennig, N. (1984) Dissimilatory Sulfate- or Sulfur-Reducing Bacteria. Bergey’s Manual of Systematic Bacteriology, 1, 663-679.

[22] Marquez-Rocha, F.J., Hernandez-Rodriguez, V. and Lamela, M.T. (2001) Biodegradation of Diesel Oil in Soil by a Microbial Consortium. Water, Air, and Soil Pollution, 128, 313-320. http://dx.doi.org/10.1023/A:1010392821353

[23] Panda, S.K., Kar, R.N. and Panda, C.R. (2013) Isolation and Identification of Petroleum Hydrocarbon Degrading Microorganisms from Oil Contaminated Environment. International Journal of Environmental Sciences, 3, 1314-1321.

[24] Fusey, P. and Oudot, J. (1976) Comparison of Two Methods for the Evaluation of in Vitro Biodegradation of Hydrocarbons. Material Und Organismen, 11, 241-251.

[25] Mandri, T. and Lin, J. (2007) Isolation and Characterization of Engine Oil Degrading Indigenous Microrganisms in Kwazulu-Natal, South Africa. African Journal of Biotechnology, 6, 23-27.

[26] Walworth, J., Braddock, J. and Woolard, C. (2001) Nutrient and Temperature Interactions in Bioremediation of Cryic Soil. Cold Regions Sciences and Technology, 32, 85-91. http://dx.doi.org/10.1016/S0165-232X(00)00020-3 
[27] Mohn, W.W. and Stewart, G.R. (2000) Limiting Factors for Hydrocarbons at Low Temperature in Arctic Soils. Soil Biology Biochemistry, 32, 1161-1172. http://dx.doi.org/10.1016/S0038-0717(00)00032-8

[28] Kim, S.J., Choi, D.H., Sim, D.S. and Oh, Y.S. (2005) Evaluation of Bioremediation Effectiveness on Crude OilContaminated Sand. Chemosphere, 59, 845-852. http://dx.doi.org/10.1016/j.chemosphere.2004.10.058

[29] Springgate, C.F., Mildvak, A.S., Abramson, R., Engle, J.L. and Loeb L.A. (1973) Escherchia coli Deoxyribonucleic Acid Polymerase I, a Zinc Metalloenzyme. Journal of Biological Chemistry, 248, 5987-5993.

[30] François, A. (2002) Degradation of a Recalcitrant Xenobiotic Compound: Metabolism of Methyl Tert-Butyl Ether (Mtbe) by Mycobacterium austroafricanum IFP 2012. PhD Dissertation, National Agronomique Institute of ParisGrignon, Paris.

[31] Soltani, M. (2004) Lipids Distribution and Metabolic Pathways in Four Gram-Negative Hydrocarbonoclastes, Variation in Relation to Carbon Source. PhD Dissertation, University of Paris VI, Paris.

[32] Guermouche, M.A. (2014) Molecular Characterization of the Bacteria Involved in the Biodegradation of Hydrocarbons. PhD Dissertation, University of Oran, Oran.

[33] Celik, G.Y., Aslim, B. and Beyatli, Y. (2008) Enhanced Crude Oil Biodegradation and Rhamnolipid Production by Pseudomonas stutzeri Strain G11 in the Presence of Tween-80 and Triton X-100. Journal of Environmental Biology, 29, 867-870.

[34] Balba, M.T., Al-Awadhi, Y.N. and Yateem, A. (2002) Isolation and Characterization of Biosurfactant-Producing Bacteria from Oil-Contaminated Soil. Soil and Sediment Contamination, 11, 41-55. http://dx.doi.org/10.1080/20025891106682

[35] María, V.P.C. (2007) Point-Source Pollution of Soils: The Case of Service Stations in the Brussels-Capital Region. Master of Science in Environment Thesis, Free University of Brussels, Brussels.

[36] Tiehm, A. (1994) Degradation of Polycyclic Aromatic Hydrocarbons in the Presence of Synthetic Surfactants. Applied and Environmental Microbiology, 60, 58-263.

[37] Nikhil, T., Verma Deepa, V., Rohan, G. and Satish, B. (2013) Isolation, Characterization and Identification of Diesel Engine Oil Degrading Bacteria from Garage Soil and Comparison of Their Bioremediation Potential. International Research Journal of Environment Sciences, 2, 48-52.

[38] Chekroud, Z., Gouda, M.K. and Houhamdi, M. (2011) Biodegradation of Crude Oil in Marine Medium. Journal of Proteomics and Bioinformatics, 4, 231-237. http://dx.doi.org/10.4172/jpb.1000194

[39] Leahy, J.G. and Colwell, R.R. (1990) Microbial Degradation of Hydrocarbons in the Environment. Microbiological Reviews, 54, 305-315.

[40] Maldonado, D.K.L. (2009) Characterization and Origin of Trace Metals, Polycyclic Aromatic Hydrocarbons and Pesticides Transported by Atmospheric Deposition and Runoff in the Peri-Urban Sanitary Watersheds. PhD Dissertation, University of Nantes, Nantes. 